\title{
Contribution of EARLINET/ACTRIS to the summer 2013 Special Observing Period of the ChArMEx project: monitoring of a Saharan dust event over the western and central Mediterranean
}

M. Sicard ${ }^{(1,2)}$, R. Barragan ${ }^{(1,2)}$, C. Muñoz-Porcar ${ }^{(1)}$, A. Comerón ${ }^{(1)}$, M. Mallet $^{(3)}$, F. Dulac ${ }^{(4)}$, J. Pelon ${ }^{(5)}$, L. Alados-Arboledas ${ }^{(6,7)}$, A. Amodeo ${ }^{(8)}$, A. Boselli $^{(8,9)}$, J. A. Bravo-Aranda ${ }^{(6,7)}$, G. D'Amico ${ }^{(8)}$, M. J. GranadosMuñoz $^{(6,7)}$, G. Leto ${ }^{(10)}$, J. L. Guerrero-Rascado ${ }^{(6,7)}$, F. Madonna ${ }^{(8)}$, L. Mona $^{(8)}$, G. Pappalardo ${ }^{(8)}$, M. R. Perrone ${ }^{(11)}$, P. Burlizzi ${ }^{(11)}$, F. Rocadenbosch $^{(1,2)}$, A. Rodríguez-Gómez ${ }^{(1)}, \mathrm{S}_{\text {. Scollo }}^{(12)}$, N. Spinelli( ${ }^{(9,13)}$, G.

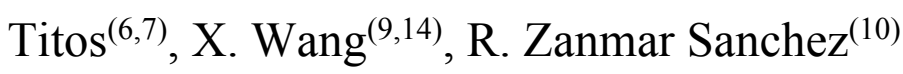

1. Remote Sensing Laboratory, Universitat Politècnica de Catalunya, Barcelona, Spain

2. Ciències i Tecnologies de l'Espai - Centre de Recerca de l'Aeronàutica i de l'Espai / Institut d'Estudis Espacials de Catalunya (CTE-CRAE / IEEC), Universitat Politècnica de Catalunya, Barcelona, Spain

3. Centre National de Recherches Météorologiques, Toulouse, France

4. Laboratoire des Sciences du Climat et de l'Environement, Saclay, France

5. Laboratoire Atmosphères, Milieux, Observations Spatiales (LATMOS), Université Pierre et Marie Curie, Paris, France

6. Dpt. Applied Physics, Faculty of Sciences, University of Granada, Fuentenueva s/n, 18071, Granada, Spain

7. Andalusian Institute for Earth System Research (IISTA-CEAMA), Avda. del Mediterráneo s/n, 18006, Granada, Spain

8. Consiglio Nazionale delle Ricerche - Istituto di Metodologie per l Analisi Ambientale (CNR-IMAA), Potenza, Italy 
9. Consorzio Nazionale Interuniversitario per le Scienze Fisiche della Materia, Naples, Italy

10. INAF - Osservatorio Astrofisico di Catania, Italy

11. Dipartimento di Matematica e Fisica, Università del Salento, Lecce, Italy

12. Istituto Nazionale di Geofisica e Vulcanologia, Osservatorio Etneo, Sezione di Catania, Italy

13. Dipartimento di Fisica, Università di Napoli "Federico II", Naples, Italy

14. Consiglio Nazionale delle Ricerche - Istituto Superconduttori, Materiali Innovativi e Dispositivi (SPIN-CNR), Italy

Corresponding author: $\quad$ Michaël Sicard

UPC, Dept. TSC

c/ Jordi Girona, 1-3, Edif. D4-007

08034, Barcelona, Spain

Email:msicard@tsc.upc.edu 


\title{
Contribution of EARLINET/ACTRIS to the summer 2013 Special Observing Period of the ChArMEx project: monitoring of a Saharan dust event over the western and central Mediterranean
}

\begin{abstract}
In the framework of the ChArMEx (Chemistry-Aerosol Mediterranean Experiment, http://charmex.lsce.ipsl.fr/) initiative, a field campaign took place in the western Mediterranean Basin between 10 June and 5 July 2013 within the ADRIMED (Aerosol Direct Radiative Impact on the regional climate in the MEDiterranean region) project. The scientific objectives of ADRIMED are the characterization of the most common "Mediterranean aerosols" and their direct radiative forcing (column closure and regional scale). During 15 - 24 June a multiintrusion dust event took place over the western and central Mediterranean Basin. Extra measurements were carried out by some EARLINET/ACTRIS (European Aerosol Research Lidar Network / Aerosols, Clouds, and Trace gases Research InfraStructure Network, http://www.actris.net/) lidar stations in Spain and Italy, in particular on 22 June in support to the flight over southern Italy of the Falcon 20 aircraft involved in the campaign. This paper describes the dust physical and optical properties observed at the different lidar stations in terms of dust plume center of mass, optical depth, lidar ratio and particle depolarization ratio. To link the differences found to the origin of dust plumes the results are discussed on the basis of backtrajectories and air- and spaceborne lidars. This work puts forward the collaboration between a European research infrastructure (ACTRIS) and an international project (ChArMEx) on topics of interest for both parties, and more generally for the atmospheric community.
\end{abstract}

Keywords: international field campaign; mineral dust physical and optical properties; Mediterranean region

\section{Introduction}

The Mediterranean basin is located at the crossroads of air masses carrying both natural (desertic particles, sea salt, volcanic ashes, etc.) and anthropogenic (black carbon, sulfate, etc.) from continental and ocean sources (Lelieveld et al. 2002). Most global and regional climate simulations have investigated the impact of global warming on the Mediterranean climate without detailed considerations on the possible radiative influence of the different 
Mediterranean aerosols. However such aerosols have a non-negligible surface, top of the atmosphere (TOA) and atmospheric radiative forcing in that region (Mallet et al. 2016). There is a need to better quantify their influence on the regional hydrological cycle, cloud cover, precipitations and atmospheric radiative budget.

In that context the Chemistry-Aerosol Mediterranean Experiment (ChArMEx; http:charmex.lsce.ipsl.fr) (Dulac et al. 2012), an international cooperative program investigating Mediterranean regional chemistry-climate interactions, organized in conjunction with the Aerosol Direct Radiative Forcing on the Mediterranean Climate (ADRIMED) project a special observing period (SOP-1a) with airborne measurements in summer 2013 in the western and central Mediterranean basin. The main campaign's objective was to gather an innovative database of the aerosol physical, chemical, optical properties in order to 1 ) estimate precisely $1 \mathrm{D}$ local direct radiative forcing and constrain 3D regional climate models, and 2) investigate how the modifications of the radiative budget (especially at the sea-surface) due to aerosols affect the sea-surface evaporation fluxes and the Mediterranean hydrological cycle during the dry season.

During the campaign a few EARLINET/ACTRIS (European Aerosol Research Lidar Network / Aerosols, Clouds, and Trace gases Research InfraStructure Network, http://www.actris.net/) lidar stations gave support to the measurements, especially during a multi-intrusion dust event that took place over the western and central Mediterranean Basin between 15 and 24 June. The objective of the paper is to show the collaboration between a European research infrastructure (ACTRIS) and an international project (ChArMEx) on topics of interest for both parties, and more generally for the atmospheric community. The interactions and complementarities of both EARLINET/ACTRIS and ChArMEx are put forward with the detailed 4D (spatio-temporal) monitoring of the dust event. The paper presents the ChArMEx project as well as the summer 2013 field 
campaign, describes the EARLINET measurements made in that context and shows the detailed 4D monitoring of the mineral dust event covered simultaneously by EARLINET ground-based and ChArMEx airborne lidar measurements. In addition backtrajectory simulations and spaceborne lidar measurements are used to characterize the multiintrusion aspect of the dust event.

\section{The ChArMEx project and the summer 2013 field campaign}

\subsection{The ChArMEx project}

The international project ChArMEx (Chemistry-Aerosol Mediterranean Experiment) is a French initiative whose goal is a scientific assessment of the present and future state of the atmospheric environment in the Mediterranean Basin, and of its impacts on the regional climate, air quality, and marine biogeochemistry. The target of ChArMEx is short-lived particulate and gaseous tropospheric trace species. The major stake is an understanding of the future of the Mediterranean region in a context of strong regional anthropogenic and climatic pressures (Dulac et al. 2012).

Through seven work packages, ChArMEx addresses: emissions and source apportionment; chemical ageing of air masses with a focus on the formation of secondary organic aerosols; transport processes and their effect on air quality; direct radiative forcing by aerosols and its consequences on the water budget and regional climate; atmospheric deposition of nutrients and contaminants; recent trends and variability in atmospheric composition; and the future evolution of atmospheric chemistry at the horizon of 2030 and 2050.

\subsection{The ChArMEX/ADRIMED summer 2013 field campaign}

The SOP-1a field campaign took place between 12 June and 5 July 2013. Activities were mainly conducted in the western Mediterranean. The teams were deployed on seven sites 
including ground measurement stations, balloon launch pad and aircraft bases: two super sites (Ersa, Corsica, and Lampedusa, Italy) and 5 secondary sites (Granada, Barcelona and Minorca in Spain, Montesoro in Corsica, and Capo Granitola in Italy). The campaign focused on aerosol direct radiative forcing (column closure and regional scale).

Both research aircraft involved, the ATR-42 and the Falcon 20 (F20), were based in Cagliari, Italy. The LEANDRE Nouvelle Generation (LNG) lidar onboard the F20 was used in its backscatter configuration, i.e. 3 elastic ( $\beta$ ) channels and 1 depolarization ( $\delta)$ channel $(3 \beta+\delta)$. Ground-based in-situ measurements were performed at several surface stations, including Ersa, Lampedusa, Granada, Capo Granitola and Minorca, while remote sensing measurements were performed at all stations except in Capo Granitola. Sounding/drifting balloons equipped with an ozone sonde and/or an optical particle counter were launched from Minorca. More details about the campaign can be found in Mallet et al. (2016).

\section{EARLINET support}

EARLINET is the aerosol profiling component of the ACTRIS European project (Pappalardo et al. 2014). In total six EARLINET lidar stations gave support to the SOP1a: Granada and Barcelona as secondary sites, and more occasionally Naples, Serra La Nave, Potenza and Lecce in south Italy (see Figure 1). From west to east:

- GR, Granada, Spain $\left(3.61^{\circ} \mathrm{W}, 37.16^{\circ} \mathrm{N}, 680 \mathrm{~m}\right.$ asl) employs a 3 elastic, 2 Raman $(\alpha)$ channels and 1 depolarization channel $(1 \beta+2 \alpha+1 \delta)$ system.

- BA, Barcelona, Spain (2.11 $\mathrm{E}, 41.39^{\circ} \mathrm{N}, 115 \mathrm{~m}$ asl $)$ employs a 3 elastic, 2 Raman channels and 1 water vapor (WV) channel $(3 \beta+2 \alpha+\mathrm{WV})$ system.

- NA, Naples $\left(14.18^{\circ} \mathrm{E}, 40.84^{\circ} \mathrm{N}, 118 \mathrm{~m}\right.$ asl), employs a $2 \beta+1 \delta$ system. 
- SN, Serra La Nave, Sicily $\left(14.97^{\circ} \mathrm{E}, 37.68^{\circ} \mathrm{N}, 1735 \mathrm{~m}\right.$ asl) employs a $1 \beta+1 \delta$ system.

- PO, Potenza $\left(15.72^{\circ} \mathrm{E}, 40.60^{\circ} \mathrm{N}, 760 \mathrm{~m}\right.$ asl) employs a $3 \beta+2 \alpha+1 \delta$ system.

- LE, Lecce $\left(18.10^{\circ} \mathrm{E}, 40.30^{\circ} \mathrm{N}, 30 \mathrm{~m}\right.$ asl) employs a $3 \beta+2 \alpha+1 \delta+\mathrm{WV}$ system.

With regard to the geographical distribution of the ChArMEx/ADRIMED super and secondary sites, the EARLINET stations from south Italy nicely close the perimeter of the WMB. Figure 1 also indicates the stations with a co-located AERONET (Aerosol Robotic Network) sun-photometer. The most relevant participation of those stations was during the aircraft operations. They are listed in Table 1. A total of eight flights overpassed or passed in the vicinity of the ground-based lidars. The flight trajectories can be found in Mallet et al. (2016). EARLINET lidar data can be found at and downloaded from the ACTRIS data center at http://www.actris.eu/DataServices/Data/DataCentre.aspx.

\section{Results and discussion}

\subsection{Event overview and data preparation}

Figure 2 shows the MSG/SEVIRI (Meteosat Second Generation / Spinning Enhanced Visible and Infrared Imager) daily mean aerosol optical depth (AOD) at $550 \mathrm{~nm}$ over ocean and gives an overview of the horizontal distribution of the dust plumes during the period of the event. The first intrusion enters southern Spain on 15 June and travels eastwards. On 20 June the plume with the highest AOD is over the western coasts of Corsica and Sardinia and a new intrusion appears over the coasts of Tunisia. On 22 June the second intrusion seems to have reached Sicily but not southern continental Italy.

Figure 3 gives an overview of the AERONET AOD at $440 \mathrm{~nm}$ and the Angström 
exponent (AE) calculated between the wavelength of 440 and $675 \mathrm{~nm}$. Level 2.0 data were used, except in Barcelona where only level 1.5 data were available. There are no AERONET data available in Granada outside of the dust event while there are no data during the event in Barcelona. The presence of dust at each site, indicated by red boxes in Figure 3, was evaluated by means of:

- The linear particle depolarization ratio (LPDR) profile (when available).

- $\quad$ The MSG/SEVIRI near-real time AOD at $550 \mathrm{~nm}$ provided every 15 minutes.

- Backtrajectories calculated with the HYSPLIT (Hybrid Single Particle Lagrangian Integrated Trajectory Model) model operated by the NOAA-ARL (National Oceanic and Atmospheric Administration - Air Resources Laboratory). The backtrajectories were calculated for 72 hours with the $1-^{\circ}$ Global Data Assimilation System (GDAS) archives. Arriving heights were varied in the range $0.6-11 \mathrm{~km}$.

- Dust load maps, vertical cross sections and concentration profiles from the BSCDREAM8bv2 (Dust REgional Atmospheric Model) model operated by the Barcelona Supercomputing Center (http://www.bsc.es/projects/earthscience/BSC-DREAM/). Those maps have a resolution of 6 hours.

The AOD is not reaching high values during the whole event: in Potenza and Lecce the AOD reaches values that are similar or lower during the event than on the previous days. During the dust event, maxima of AOD 440 (the AOD at $440 \mathrm{~nm}$ ) of 0.29 (AE around 0.50), 0.17 (AE around 0.66) and 0.37 (AE around 0.80) are found in Granada (on 16 June around noon), in Potenza (on 21 June around 17UT) and Lecce (on 23 June 
around 05UT), respectively. According to this first analysis SEVIRI AOD seems to be overestimated with respect to AERONET AOD. This overestimation was recently quantified as $+35 \%$ by Chazette et al. (2016).

The lidar measurements falling into the period of interest (red boxes in Figure 3) have been inverted: daytime measurements were inverted with the two-component algorithm and a given lidar ratio (Fernald 1984; Sasano and Nakane 1984; Klett 1985) while the nighttime measurements were inverted with the elastic-Raman algorithm (Ansmann, Riebesell, and Weitkamp 1990). Each group provided the inversions retrieved with their own algorithms. For that reason, the daytime profiles were inverted with different values of lidar ratios. For example, at $532 \mathrm{~nm}$, constant values of 55,50 and 45 sr were used in Granada, Barcelona and Potenza, respectively. A synthetic profile of values ranging between 44 and 65 sr was used in Naples and Serra La Nave (at 355 $\mathrm{nm})$, respectively. In Lecce a height-independent value of $60-80 \mathrm{sr}$ was used as a function of the hour of the day. From the profiles of the backscatter coefficient, $\beta$, at 532 $\mathrm{nm}(355 \mathrm{~nm}$ in the case of Serra La Nave) and of the linear particle depolarization ratio $(\delta)$ at $532 \mathrm{~nm}(355 \mathrm{~nm}$ in the case of Serra La Nave and Lecce) we retrieved the tropospheric dust layer bottom and top heights, $h_{\text {bottom }}$ and $h_{\text {top }}$, respectively, as well as the height of their center of mass, $h_{\mathrm{CM}}$, by applying the following criteria:

- In case of marked transitions (planetary boundary layer (PBL) - dust layer and dust layer - free troposphere (FT)), we looked for a sharp peak of the first

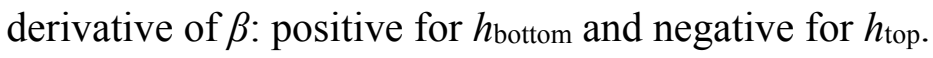

- Near the top of the dust layer, when $\beta$ decreases very slowly with increasing height, the criterion previously described was not sufficient. Thus we smoothed the profile with a 5-point sliding window in order to avoid negative values due to 
the noise, and we determined $h_{\text {top }}$ as the height at which the smoothed backscatter was two orders of magnitude $\left(10^{-2}\right)$ lower than the maximum backscatter in the dust layer.

- When the dust layer is coupled to the PBL, we looked for a sharp positive peak of the first derivative of $\delta$.

Those heights, as well as the AOD of the dust layer at $532 \mathrm{~nm}, \mathrm{AOD}_{532}^{\mathrm{MD}}$, and the mean extinction coefficient at $532 \mathrm{~nm}$ in the dust layer, $\bar{\alpha}_{532}^{\mathrm{MD}}$, are reported in Table 2. Figure 4 shows the color plot of $\mathrm{AOD}_{532}^{\mathrm{MD}}$ as a function of altitude and time.

\subsection{Results}

There is a clear temporal evolution of the dust AOD as the dust plumes travel from west to east (Figure 4 and Table 2). Higher $\mathrm{AOD}_{532}^{\mathrm{MD}}$ are observed in the Iberian Peninsula (IP) than in southern Italy. If we disregard the second half (after 12 UT) of the Barcelona profiles of 17 June that may be contaminated with clouds forming at the dust layer top, the highest values of $\mathrm{AOD}_{532}^{\mathrm{MD}}$ (around 0.28) are reached in Barcelona in the morning of 17 June. The mean dust AOD is twice larger in Naples (0.17) than in the rest of the southern Italy stations. The mean extinction coefficient in the dust layer is approximately twice larger in the IP than in southern Italy. Except in Barcelona where clouds may have contaminated the aerosol profile after $12 \mathrm{UT}$ on 17 June, the AOD in the dust layer is quite constant with time: the standard deviations are lower than 0.04 .

The dust vertical distribution is also quite stable with time although it differs from one site to another. The vertical extension is important as in most of the stations the top of the dust layer exceeds $6 \mathrm{~km}$. $h_{\text {bottom, }} h_{\text {top }}$ and $h_{\mathrm{CM}}$ are very similar in Granada and Barcelona. In both stations the dust is well mixed in the layer since the center of mass is close to the geometrical center of the layer. In general $h_{\text {bottom }}$ is higher in southern Italy 


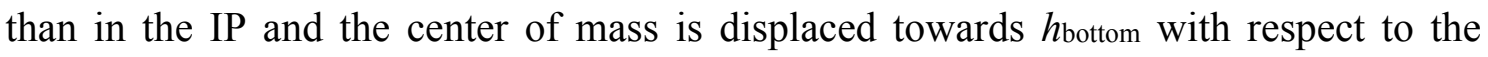
geometrical center of the layer (see Naples and Potenza in Figure 4). We observe two very different vertical distributions between Serra La Nave, situated at $1735 \mathrm{~m}$ asl, where the dust plume is found in average between 4.3 and $6.3 \mathrm{~km}$, and Lecce where the dust plume is found in average between 2.1 and $4.6 \mathrm{~km}$.

From all the profiles available we selected a case at each station with a high dust load and plot the optical profiles in Figure 5. Nighttime measurements were available only in Granada and Potenza. In the rest of the stations the measurements were inverted with the two-component algorithm. Consequently the lidar ratios and the extinction-related AE are not plotted. A clear signature of dust is present in all plots. The maxima of the extinction coefficient are larger in Granada (around $\left.150 \mathrm{Mm}^{-1}\right)$ than in Potenza $\left(85 \mathrm{Mm}^{-}\right.$ $\left.{ }^{1}\right)$. The extinction-related $\mathrm{AE}$ is close to 0 at both stations. Both lidar ratios at 355 and $532 \mathrm{~nm}$ are very similar: in Granada the profiles start at $80 \mathrm{sr}$ and decrease to finally oscillate around $50 \mathrm{sr}$; in Potenza the profiles start at 30-35 sr and increase to finally oscillate around $50 \mathrm{sr}$ at $355 \mathrm{~nm}$ and around $60 \mathrm{sr}$ at $532 \mathrm{~nm}$. In turn the LPDR are different and might indicate different dust origin or mixing: it oscillates between $0.20-$ 0.27 in Granada and between $0.26-0.33$ in Potenza. In Naples the LPDR is similar to the one in Potenza between 2 and $4 \mathrm{~km}$. In Lecce and Serra La Nave the LPDR (at 355 $\mathrm{nm}$ ) is quite constant around 0.26 and around 0.2 , respectively. In Serra La Nave a single, well-defined layer is observed between 4.37 and $6.23 \mathrm{~km}$.

For all cases plotted in Figure 5 we calculated 72-hour backtrajectories with the HYSPLIT model. They are represented in Figure 6. Almost on all of them there is a clear origin from the Saharan region. The trajectories arriving in Granada at $2.5 \mathrm{~km}$ and in Barcelona at $4.4 \mathrm{~km}$ are similar and clearly originate from northern Sahara in Algeria. In Naples the trajectories come from the west-southwest. Like in Granada and Barcelona, 
Figure 6(c) indicates a dust origin from northern Sahara for the dust arriving in Naples. The comparison of those trajectories with the MSG/SEVIRI AOD (Figure 2) suggests that the dust plume arriving in Naples comes directly from the source region without traveling over the Mediterranean. It is therefore very unlikely that the dust plume arriving in Naples might have previously travelled over the IP. Finally the trajectories in Serra La Nave, Potenza and Lecce originate mostly from the northern part of the Sahara situated at the corner of northeastern Algeria, south Tunisia and northwestern Libya. Only two trajectories, the ones arriving at the highest altitudes in Serra la Nave (at 5.0 and $6.1 \mathrm{~km}$ ) which are similar to the trajectories in Naples, are coming from the west and thus might be associated with the first intrusion. In the near-future we expect to simulate more quantitative dispersion model runs including full turbulence and convection with the FLEPART (FLEXible PARTicle dispersion model) model in order to be able to retrieve all possible trajectories of the dust plume arriving at the stations. So far, this analysis shows that the first intrusion detected first over the IP finds its origin in northern Sahara in Algeria and that the second intrusion detected only in south Italy finds its origin in the Saharan region situated at the corner of northeastern Algeria, south Tunisia and northwestern Libya.

In order to further investigate the situation in southern Italy about the potential presence and mixing of both intrusions, airborne and spaceborne observations are used. Figure 7 shows the quicklook of attenuated backscatter at $532 \mathrm{~nm}$ from the LNG lidar onboard the F20 aircraft on 22 June between approximately 10:30 and 13:00 UT. The flight track is shown in the left plot of Figure 8. From almost the beginning of the flight until the latitude of Serra La Nave a lofted layer is clearly visible between roughly 4 and $6.5 \mathrm{~km}$. Indeed in Serra La Nave a unique layer is detected at 11:19 UT between 4.5 and $6.5 \mathrm{~km}$ (reported in Figure 7 with small horizontal white ticks). $\mathrm{AOD}_{532}^{\mathrm{MD}}$ is 0.03 and the 
mean LPDR at $355 \mathrm{~nm}$ is 0.20 . It appears that this layer is strictly associated with the second intrusion. When the aircraft flew over southern Italy a strong layer was observed from the ground up to approximately $4 \mathrm{~km}$ and then up to $5-6 \mathrm{~km}$. This horizontal distribution agrees with the local observations in Lecce at 11:48 UT (despite the distance between Lecce and the flight track, approximately $100 \mathrm{~km}$ ) where the plume is detected between 2.0 and $4.7 \mathrm{~km}\left(\mathrm{AOD}_{532}^{\mathrm{MD}}\right.$ around 0.12 and $\delta_{355}$ around 0.26$)$ and the ones in Naples at 12:21 UT where the plume is detected between 0.9 and $6.9 \mathrm{~km}\left(\mathrm{AOD}_{532}^{\mathrm{MD}}\right.$ around 0.20 and $\delta_{532}$ around $\left.0.20-0.35\right)$. No measurement is available in Potenza. It is most probable that the dust plume observed in Naples is only associated to the first intrusion while in Lecce the plume from both intrusions may be present. If we look at the highest layer in Lecce between 3.3 and $4.5 \mathrm{~km}$ in Figure 5(f) it has a LPDR at $355 \mathrm{~nm}$ of 0.26 , while the one at Serra La Nave (Figure $5(d)$ ) between 4.4 and $6.2 \mathrm{~km}$, constant during the whole day, has a LPDR around 0.20. This LPDR higher in Lecce than in Serra La Nave indicates that if the dust of the second intrusion has reached Lecce, it is mixed with dust from different origin and most probably with dust from the first intrusion. In the left plot of Figure 8 we also reported the CALIPSO (Cloud-Aerosol Lidar and Infrared Pathfinder Satellite Observation) overpass track during the previous night, i.e. on 22 June around 01 UT. The overpass track passed east of Potenza and Serra La Nave where the measurement closest in time is at 23:40 UT (on 21 June) and at 10:48 UT, respectively. The height of the dust layers detected at both stations are reported on the quicklook of the LPDR at 532 nm measured by the CALIOP (Cloud-Aerosol Lidar with Orthogonal Polarization) lidar onboard CALIPSO and reported on the right plot of Figure 8 . One sees a rather homogeneous depolarizing plume with a large horizontal distribution extending from Africa to central Europe. Over the Mediterranean Sea and the African continent this plume is rather thin, thickness of about $1-1.5 \mathrm{~km}$, high, altitude $>2.5 \mathrm{~km}$, and not 
connected to the ground. This result suggests that this plume is already advected and finds its origin probably in a region west of the satellite track according to the horizontal transport seen in Figure 2. It is the same plume observed by the LNG lidar south of Sicily (Figure 7). One sees also clearly how the plume extends down to the surface over the Adriatic Sea. The height of the dust plume detected in Potenza at 23:40 UT on 21 June is reported on the CALIOP quicklook by small, horizontal, white ticks: the layer is detected between 1.8 and $5.4 \mathrm{~km}\left(\mathrm{AOD}_{532}^{\mathrm{MD}}\right.$ around 0.10 and $\delta_{532}$ around $\left.0.26-0.33\right)$. The agreement with the depolarizing layer observed by CALIOP is quite good. The measurement at Serra la Nave of 10:48 UT $\left(4.4<\right.$ dust layer $<5.9 \mathrm{~km}, \mathrm{AOD}_{355}^{\mathrm{MD}}$ around 0.01 and $\delta_{355}$ around 0.2 ) indicates that the lofted plume has either been advected during the night and the morning, or that the flanks of Mount Etna (3329 m high) close to which the Serra La Nave station is installed $(<10 \mathrm{~km})$ acts as a ramp for the air masses travelling northwards (Serra La Nave is situated upwind of Mount Etna with respect to the second intrusion). The dust plume LPDR at $532 \mathrm{~nm}$ from the CALIOP quicklook is rather homogeneous and ranges between 0.10 and 0.30 . It does not allow distinguishing the different dust plumes of the scene. Further analysis with higher level products of CALIOP and possibly spatial integration will hopefully help to distinguish both types of mineral dust observed by the ground-based lidar stations.

\section{Conclusions}

A dust transport event of moderate intensity has been observed by EARLINET stations during the SOP-1a of the 2013 ChArMEx/ADRIMED field campaign. A first intrusion which hits first Spain is transported over the western Mediterranean Basin and reaches some of the southern Italy stations. The arrival of that plume over southern Italy coincides with a second intrusion out of the coast of Tunisia. This second intrusion only reaches the southernmost (Serra La Nave) and easternmost (Potenza and Lecce) Italian stations. 
Larger values of AOD in the dust layer were found over Spain $(0.21-0.22)$ than over southern Italy $(0.07-0.17)$. The vertical distribution is very similar in both Spanish sites while it is more heterogeneous over Italy. At the end of its transport over the Mediterranean Sea, the dust plume in Naples reaches almost $7.5 \mathrm{~km}$ high.

Surprisingly the depolarization ratio at $532 \mathrm{~nm}$ is found slightly higher over Naples and Potenza $(0.26-0.33)$ than over Granada $(0.2-0.27)$. The dust plume from the second intrusion observed in Serra La Nave has a depolarization ratio of 0.20 at 355 nm. Lidar ratio values over Spain and Italy are found in accordance with the literature close to 50-60 sr. Backtrajectories and air- and spaceborne lidars have proved extremely useful to understand the horizontal distribution of the different dust plumes observed by the ground-based lidar stations.

This work puts forward the collaboration between a European research infrastructure (ACTRIS) and an international project (ChArMEx) on topics of interest for both parties, and more generally for the atmospheric community.

\section{Acknowledgements}

This study was performed in the framework of workpackage 4 on aerosol-radiation-climate interactions of the coordinated program ChArMEx (the Chemistry-Aerosol Mediterranean Experiment; http://charmex.lsce.ipsl.fr). EARLINET measurements were supported by the ACTRIS (Aerosols, Clouds, and Trace Gases Research Infrastructure Network) Research Infrastructure Project funded by the European Union's Horizon 2020 research and innovation programme under grant agreement n. 654169 and previously under grant agreement n. 262254 in the 7th Framework Programme (FP7/2007-2013). Measurements in Barcelona were also supported by the Spanish Ministry of Economy and Competitivity (projects TEC2012-34575 and TEC2015-63832-P) and of Science and Innovation (project UNPC10-4E-442) and EFRD (European Fund for Regional Development) and by the Department of Economy and Knowledge of the Catalan autonomous government (grant 2014 SGR 583). In Granada measurements were 
supported by the Andalusia Regional Government (projects P12-RNM-2409 and P10-RNM6299). ChArMEx-France is supported through the MISTRALS program by INSU, ADEME, Météo-France, and CEA. The ADRIMED project was mainly supported by the French Agence Nationale de la Recherche.

\section{References}

Ansmann, A., M. Riebesell, and C. Weitkamp. 199. "Measurement of atmospheric aerosol extinction profiles with a Raman lidar". Opt. Letters 15 (13): 746 - 748.

Chazette, P., J. Totems, G. Ancellet, J. Pelon, and M. Sicard. 2016. "Temporal consistency of lidar observables during aerosol transport events in the framework of the ChArMEx/ADRIMED campaign at Menorca Island in June 2013". Atmos. Chem. Phys. 16: 2863-2875. doi: 10.5194/acp-16-2863-2016.

Dulac, F., T. Agacayak, L. Alados Arboledas, A. Alastuey, Z. Ameur, G. Ancellet, E.-M. Assamoi, et al., .2012. "An update on ChArMEx (the Chemistry-Aerosol Mediterranean Experiment) activities and plans for aerosol studies in the Mediterranean region". Paper presented at the European Aerosol Conference, Granada, Spain, September 2-7.

Fernald, F. G. 1984. "Analysis of atmospheric lidar observations: some comments". Appl. Opt. 23: 652-653.

Klett, J. D. 195. "Lidar inversion with variable backscatter/extinction ratios". Appl. Opt. 24: $1638-1643$.

Lelieveld, J., H. Berresheim, S. Borrmann, P.J. Crutzen, F.J. Dentener, H. Fischer, J. Feichter, et al. 2002. "Global air pollution crossroads over the Mediterranean", Science 298: 794-799. doi: 10.1126/science.1075457.

Mallet, M., F. Dulac, P. Formenti, P. Nabat, J. Sciare, G. Roberts, J. Pelon, et al. 2016. "Overview of the Chemistry-Aerosol Mediterranean Experiment/Aerosol Direct Radiative Forcing on the Mediterranean Climate (ChArMEx/ADRIMED) summer 2013 campaign". Atmos. Chem. Phys. 16: 455-504. doi: 10.5194/acp-16-455-2016, 2016. 
Pappalardo, G., A. Amodeo, A. Apituley, C. Comeron, F. Freudenthaler, H. Linné, A. Ansmann, et al. 2014. "EARLINET: towards an advanced sustainable European aerosol lidar network”, Atmos. Meas. Tech. 7: 2389-2409. doi:10.5194/amt-7-2389-2014.

Sasano, Y., and H. Nakane. 1984. "Significance of the extinction/backscatter ratio and the boundary value term in the solution for the two-component lidar equation". Appl. Opt. 23: 11-13. 


\begin{tabular}{|c|c|c|c|c|c|c|c|c|}
\hline Aircraft & ATR42 & ATR42 & F20 & F20 & ATR42 & F20 & F20 & F20 \\
\hline Flight no. & F30 & F31 & F13 & F16 & F36 & F17 & F18 & F19 \\
\hline Day of June & $16 / \mathrm{pm}$ & $17 / \mathrm{am}$ & $18 / \mathrm{pm}$ & $22 / \mathrm{am}$ & $22 / \mathrm{pm}$ & $23 / \mathrm{am}$ & $24 / \mathrm{am}$ & $27 / \mathrm{am}$ \\
\hline GR, $3 \beta+2 \alpha+1 \delta$ & & & & & & & & \\
\hline$B A, 3 \beta+2 \alpha+W V$ & & & & & & & & \\
\hline$N A, 2 \beta+1 \delta$ & & & & & & & & \\
\hline$S N, 1 \beta+1 \delta$ & & & & & & & & \\
\hline$P 0,3 \beta+2 \alpha+1 \delta$ & & & & & & & & \\
\hline LE, $3 \beta+2 \alpha+1 \delta+W V$ & & & & & & & & \\
\hline
\end{tabular}

Table 1. EARLINET measurements coincident with ChArMEx/ADRIMED aircraft. The EARLINET stations are ordered from west to east. 'am' and 'pm' stand for morning and afternoon, respectively. 


\begin{tabular}{|c|c|c|c|c|c|c|c|}
\hline \hline & Unit & Granada & Barcelona & Naples & $\begin{array}{c}\text { Serra La } \\
\text { Nave }\end{array}$ & Potenza & Lecce \\
\hline $\begin{array}{c}\text { Number of } \\
\text { profiles }\end{array}$ & & 3 & 13 & 9 & 8 & 4 & 8 \\
$h_{\text {bottom }}$ & $\mathrm{km}$ & $1.5 \pm 0.3$ & $1.6 \pm 0.6$ & $0.9 \pm 0.1$ & $4.3 \pm 0.2$ & $1.7 \pm 0.2$ & $2.1 \pm 0.0$ \\
$h_{\text {top }}$ & $\mathrm{km}$ & $5.4 \pm 0.2$ & $5.4 \pm 1.4$ & $6.8 \pm 0.6$ & $6.3 \pm 0.3$ & $5.5 \pm 0.9$ & $4.6 \pm 0.1$ \\
$h_{\mathrm{CM}}$ & $\mathrm{km}$ & $3.3 \pm 0.3$ & $3.5 \pm 0.5$ & $3.1 \pm 0.5$ & $5.2 \pm 0.1$ & $2.9 \pm 0.6$ & $3.5 \pm 0.1$ \\
$\mathrm{AOD}_{532}^{\mathrm{MD}}$ & & $0.21 \pm 0.02$ & $0.22 \pm 0.11$ & $0.17 \pm 0.03$ & $0.07 \pm 0.04$ & $0.07 \pm 0.03$ & $0.10 \pm 0.01$ \\
$\bar{\alpha}_{532}^{\mathrm{MD}}$ & $\mathrm{Mm}^{-1}$ & $55 \pm 10$ & $65 \pm 31$ & $28 \pm 6$ & $32 \pm 14$ & $18 \pm 8$ & $39 \pm 5$ \\
\hline \hline
\end{tabular}

Table 2. Dust layer mean structural and optical properties. $\bar{\alpha}_{532}^{\mathrm{MD}}$ represents the mean extinction coefficient in the dust layer. The associated error is the standard deviation. 
Figure captions

Figure 1. EARLINET lidar stations (red stars) involved during SOP-1a.

Figure 2. MSG/SEVIRI daily mean AOD at $550 \mathrm{~nm}$ over ocean retrieved from the ICARE Thematic Center (www.icare.univ-lille1.fr). The AOD color bar is reported in the bottom right corner.

Figure 3. AERONET AOD440 (blue circles, left axis) and AE440-675 (green crosses, right axis) during 15-25 June 2013. The red rectangles indicate the presence of mineral dust over the site. There is no AERONET data in Serra La Nave and no sun-photometer instrument in Naples.

Figure 4. Mineral dust $\mathrm{AOD}$ at $532 \mathrm{~nm}, \mathrm{AOD}_{532}^{\mathrm{MD}}$, (at $355 \mathrm{~nm}$ in Serra La Nave) as a function of altitude and time during June 2013. The red rectangles indicate the presence of mineral dust over the site. Black crosses indicate the center of mass of the dust layer. The dust AOD color bar is reported in the right corner.

Figure 5. Optical profiles at a selected time at the six lidar stations (blue: $355 \mathrm{~nm}$, green: $532 \mathrm{~nm}$, red: $1064 \mathrm{~nm}$ ): (a) Granada on 17 June at 01UT, (b) Barcelona on 17 June at 08UT, (c) Naples on 22 June at 09UT, (d) Serra la Nave on 22 June at 13UT, (e) Potenza on 22 June at 00UT and (f) Lecce on 22 June at 12UT. 'Bck coef' and 'Ext coef' are the backscatter and extinction coefficients, respectively. In the AE plot ' $\beta-\lambda_{1} / \lambda_{2}$ ' and ' $\alpha$ $\lambda_{1} / \lambda_{2}$ ' are, respectively, the backscatter- and the extinction-related Ångström coefficients calculated between the wavelengths $\lambda_{1}$ and $\lambda_{2}$. The horizontal solid lines indicate the altitude of the station and the horizontal dash lines the dust layer bottom and top height. When daytime measurements are presented, no lidar ratios and no extinction-related AE are shown. 
Figure 6. 72-hour backtrajectories calculated with the HYSPLIT model at the stations and at the time of the selected cases of Figure 5.

Figure 7. LNG quicklook of the attenuated backscatter coefficient at $532 \mathrm{~nm}$ (in arbitrary units) on 22 June between 10:30 and 13:00 UT. The horizontal white bars indicate the height of the dust plume detected at the EARLINET stations and coincident in time. The position of the airborne lidar was approximately $10 \mathrm{~km}$ east of Serra la Nave, $100 \mathrm{~km}$ west of Lecce and $40 \mathrm{~km}$ southwest of Naples.

Figure 8. (left) Trajectory of the F20 aircraft on 22 June between 10:30 and 13:00 UT (green) and of the CALIPSO overpass on 22 June around 01 UT (red); (right) CALIOP quicklook of the particle depolarization ratio at $532 \mathrm{~nm}$. The horizontal white bars indicate the height of the dust plume detected at Potenza (on 21 June at 23:40 UT) and Serra La Nave (on 22 June at 10:48 UT). 